\title{
PENGARUH INTELLECTUAL CAPITAL TERHADAP KINERJA KEUANGAN PADA PERUSAHAAN RETAIL YANG TERDAFTAR DI BURSA EFEK INDONESIA (BEI) PADA TAHUN 2009 - 2011
}

\author{
Oleh: \\ Nono Supriatna \\ (Dosen Program Studi Akuntansi Universitas Pendidikan Indonesia) \\ Arvian Triantoro \\ (Dosen Program Studi Akuntansi Universitas Pendidikan Indonesia) \\ Rukniati Rustandi \\ (Alumni Program Studi Akuntansi Universitas Pendidikan Indonesia)
}

\begin{abstract}
The research aims to examine the influence of intellectual capital to company's financial performance (profitability, productivity, and market valuation. Profitability measured by Return On Asset (ROA), productiviy measured by Asset Turn Over (ATO), and market valuation measured by Market to Book Value (MB). Independent variabel used in this research is intellectual capital which measured by VAIC ${ }^{\mathrm{TM}}$, while dependent variable are ROA, ATO, and MB. In this research, the authors used a quantitative verificative. Data obtainable from retail company listed in Indonesia Stock Exchange (IDX) year period 2009-2011. The samples in this research using the method of purposive. Based on sampling criteria the final sample in this research is 7 retail companies. This research use simple linear regression for data analysis. From the research that has been done shows that intellectual capital has positive influence to profitability, intellectual capital has negative influence to productivity, and intellectual capital has no effect to market valuation.
\end{abstract}

Keywords:Intellectual Capital, Financial Performance, Profitability, Productivity, Market Valuation.

\section{Pendahuluan}

Perkembangan yang sangat pesat dalam bidang ekonomi membawa dampak perubahan yang nyata terhadap pengelolaan bisnis dan penentuan strategi bersaing. Agar terus bertahan, perusahaan-perusahaan harus dengan cepat mengubah bisnis berdasarkan tenaga kerja (labour based bussines) menuju bisnis berdasarkan pengetahuan (knowledge based bussines), sehingga karakteristik perusahaan berubah menjadi knowledge based bussines. Seiring dengan adanya perubahan ekonomi menjadi berkarakteristik ilmu pengetahuan dengan penerapan manajemen pengetahuan (knowledge management), maka kemakmuran suatu 
perusahaan bergantung pada suatu penciptaan transformasi dan kapitalisasi dari pengetahuan itu sendiri (Sawarjuwono dan Kadir, 2003:35).

Menurut Barney (dalam Ariawan, 2011:55) mengemukakan keunggulan kompetitif didapat dengan mengimplementasikan strategi yang mengeksploitasi keunggulan internal perusahaan, merespon kesempatan dari lingkungan sekitar dan menetralisir ancaman dari luar. Teori Resource-Based View yang dipelopori oleh Barney (dalam Mualim, 2009:2) berpandangan bahwa nilai ekonomis dan keunggulan bersaing sebuah perusahaan terletak pada kepemilikan dan pemanfaatan secara efektif sumber daya organisasi yang mampu menambah nilai (valuable), bersifat langka (rare), sulit untuk ditiru (imperfectly immitable) dan tidak tergantikan oleh sumberdaya lain (non- substitutable). Oleh karena itu, strategi bersaing diletakkan pada upaya-upaya mencari, mendapatkan, mengembangkan dan mempertahankan sumber daya strategis. Sumber daya strategis yang dimaksud adalah Intellectual capital.

Intellectual capital merupakan sesuatu yang masih baru, bukan saja di Indonesia tetapi juga di lingkungan bisnis global, hanya beberapa negara maju yang telah menerapkan konsep ini, contohnya Australia, Amerika dan Rusia. Pada umumnya kalangan bisnis masih belum menemukan jawaban yang tepat mengenai nilai lebih apa yang dimiliki perusahaan (Mualim, 2009:11). Nilai lebih ini sendiri dapat berasal dari kemampuan berproduksi suatu perusahaan sampai pada loyalitas pelanggan terhadap perusahaan (Mualim, 2009:11). Nilai lebih ini dihasilkan oleh intellectual capital yang dapat diperoleh dari budaya pengembangan perusahaan maupun kemampuan perusahaan dalam memotivasi karyawannya sehingga kinerja keuangan perusahaan dapat meningkat.

Semua jenis industri secara luas tergantung pada penggunaan knowledge sebagai bagian dari input. Tidak hanya industri keuangan, asuransi dan komunikasi yang disebut "knowledge-based industries" saja yang bergantung pada penggunaan knowledge, tetapi juga industri retail sangat bergantung pada knowledge agar dapat bersaing dengan memiliki keunggulan kompetitif.

Retail merupakan tahap akhir proses distribusi dengan dilakukannya penjualan langsung pada konsumen akhir. Bisnis Retail didefinisikan sebagai mata rantai terakhir dalam melakukan kegiatan penjualan barang dan jasa dari produsen sampai kepada konsumen akhir (Sopiah dan Syihabudhin, 2008:7). Seiring bangkitnya perekonomian global dan minat belanja konsumen yang sangat tinggi, maka bisnis di sektor retail sangat menjanjikan. Menurut pengamat ekonomi, Fauzi Ichsan (dalam Republika, 27 februari 2012) menyatakan bahwa "sektor retail adalah sektor yang akan terus tumbuh meskipun terjadi krisis global, hal ini dikarenakan karena sektor retail pertumbuhannya ditopang pertumbuhan PDB dan suku bunga global yang rendah".

Penerapan intellectual capital merupakan sesuatu yang masih baru di industri retail. Pada umumnya kalangan bisnis masih belum menemukan jawaban yang tepat mengenai nilai lebih apa yang dimiliki perusahaan. Nilai lebih ini dapat berasal dari kemampuan berproduksi suatu perusahaan sampai pada loyalitas pelanggan terhadap perusahaan. Nilai lebih ini dihasilkan oleh intellectual capital yang dapat diperoleh dari budaya pengembangan perusahaan maupun kemampuan perusahaan dalam memotivasi karyawannya sehingga produktivitas perusahaan 
dapat dipertahankan atau bahkan dapat meningkat. Nilai lebih ini sangat diperlukan oleh perusahaan retail dalam menghadapi persaingan di pasar domestik dan regional. Sangatlah penting untuk diketahui seberapa besarnya pengaruh intellectual capital pada kinerja keuangan perusahaan retail, karena intellectual capital adalah sumber keunggulan kompetitif yang berkesinambungan (Bontis, 2001:274). Selain itu sangat perlu diketahui seberapa besar pengaruh intellectual capital terhadap kinerja keuangan industri retail, sehingga perusahaan-perusahaan retail mampu meningkatkan daya saingnya.

Adanya kesulitan di dalam pengukuran intellectual capital secara langsung mengakibatkan Pulic (1998) memperkenalkan pengukuran intellectual capital secara tidak langsung dengan menggunakan Value Added Intellectual Coefficient (VAIC ${ }^{\mathrm{TM}}$ ), yaitu suatu ukuran untuk menilai efisiensi dari nilai tambah sebagai hasil dari kemampuan intelektual perusahaan. Sumber daya perusahaan yang juga merupakan komponen utama dari VAIC ${ }^{\mathrm{TM}}$ adalah physical capital (VACA - Value Added Capital Employed), human capital (VAHU - Value Added Human Capital), structural capital (STVA - Structural Capital Value Added).

Pulic (dalam Solikhah, 2010:5) menyatakan bahwa VAIC ${ }^{\text {TM }}$ dianggap memenuhi kebutuhan dasar ekonomi kontemporer dari "sistem pengukuran" yang menunjukan nilai sebenarnya dan kinerja suatu perusahaan, karena tujuan utama dalam ekonomi berdasarkan knowledge based business adalah untuk menciptakan value added. Sedangkan untuk menciptakan value added dibutuhkan ukuran yang tepat tentang physical capital (dana-dana keuangan) dan intellectual potential (direpresentasikan oleh karyawan dengan segala potensi dan kemampuan yang melekat pada mereka). Penciptaan value added pada perusahaan memungkinkan benchmarking dan dapat memprediksi kemampuan perusahaan di masa yang akan datang. Selain bagi perusahaan, value added sangat berguna bagi stakeholder di dalam value creation process (pemberi kerja, karyawan, manajemen, inverstor, pemegang saham, dan mitra bisnis) dan dapat diterapkan pada semua tingkat aktivitas bisnis. VAIC ${ }^{\mathrm{TM}}$ dapat menunjukan bagaimana physical capital dan intellectual potential telah secara efisien dimanfaatkan oleh perusahaan.

Hasil penelitian dari Firer dan Williams (2003), Chen et al. (2005), Tan et al. (2007), Suhendah (2007), Kuryanto dan Syafruddin (2008), Ulum (2008), serta Ayu (2010) masih menunjukkan hasil yang kontradiktif dan bervariasi, sehingga penulis tertarik untuk mengkaji ulang dengan melakukan penelitian mengenai pengaruh intellectual capital terhadap kinerja keuangan perusahaan dalam lingkungan industri yang berbeda dengan menggunakan pendekatan yang sama. Penelitian ini mereplikasi penelitian yang dilakukan oleh Tan et al. (2007) dengan sedikit modifikasi yang merupakan adopsi dari penelitian Firrer dan Williams (2003). Modifikasi yang dimaksud adalah proksi atas ukuran kinerja keuangan. Tan et al (2007) menggunakan Return On Equity (ROE), Earning Per Share (EPS) dan Annual Stock Return (ASR). Sedangkan penelitian ini menggunakan Return On Asset (ROA), Asset Turn Over (ATO), dan Market to Book Value (MB) yang mengacu pada penelitian Firrer dan Williams (2003). Pemilihan ROA, ATO dan MB sebagai indikator untuk kinerja keuangan perusahaan karena tiga rasio ini mewakili profitabilitas (ROA), produktivitas (ATO), dan nilai pasar (MB) agar penelitan ini dapat mendapatkan hasil yang komprehensif mengenai 
kinerja keuangan perusahaan, tidak melihat dari nilai pasar saja. Perbedaan lain penelitian ini dengan penelitian terdahulu, yaitu lokasi penelitian, objek penelitian, periode penelitian dan metode penelitian.

Penelitian Tan et al. (2007) dilakukan pada seluruh perusahaan yang terdaftar di Singapore Stock Exchange (SGX) dari berbagai jenis industri. Sedangkan penelitian ini dilakukan pada perusahaan retail yang terdaftar di Bursa Efek Indonesia (BEI). Sedangkan untuk alat analisis penelitian ini menggunakan analisis regresi linear sederhana.

\section{Kajian Pustaka}

Resource Based View (RBV) menekankan bahwa peningkatan keunggulan bersaing berasal dari sumberdaya strategis organisasi (Dierickx et. al. dalam Teece, 2003: 514). Keunggulan bersaing (competitive advantage) memungkinkan perusahaan memperoleh kinerja unggul pada jangka waktu tertentu (Pitts dan Lei, 2003: 7). Menurut Grant et. al (2002: 139) inti dari RBV adalah bahwa "perusahaan-perusahaan berbeda secara fundamental karena memiliki seperangkat sumberdaya".

Lebih jauh Cheng et al (2010) menjelaskan bahwa keunggulan kompetitif perusahaan didapat dari kemampuan perusahaan untuk menyusun dan mengeksploitasi berbagai kombinasi tertentu dari sumberdaya perusahaan. Sumberdaya tersebut dapat berwujud maupun tidak berwujud, dan sumberdaya tersebut mewakili input dalam proses produksi perusahaan; modal, perlengkapan, keahlian dari pegawai, paten, pembiayaan dan manajer yang berbakat.

Pendekatan RBV menyatakan bahwa perusahaan dapat mencapai keunggulan bersaing yang berkesinambungan dan memperoleh keunggulan superior dengan memiliki dan mengendalikan aset-aset strategis baik yang berwujud maupun yang tidak berwujud (Teece et. al., 2003: 513). Menurut pendekatan RBV, perusahaan merupakan sekumpulan sumberdaya strategis dan produktif yang unik, langka, kompleks, saling melengkapi dan sulit untuk ditiru para pesaing yang dapat dimanfaatkan sebagai elemen untuk mempertahankan strategi bersaingnya (Teece et. al., 2003: 513). Hubungan diantara bisnis-bisnis yang dimiliki perusahaan memberikan dasar ekonomis bagi organisasi multibisnis (Teece et. al., 2003: 513), dan bahwa kemampuan sebuah perusahaan untuk memperoleh sinergi dan economic of scope dari aktivitas membagi sumberdaya diantara bisnis-bisnis yang ada merupakan dasar untuk mencapai kinerja yang lebih tinggi (Barney dalam Mualim, 2009:46).

Dalam kajian mengenai intellectual capital, banyak definisi yang telah diajukan oleh para peneliti. Edvinsson dan Malone (dalam Lonnqvist, 2002: 285) menyatakan bahwa intellectual capital adalah "suatu jenis kontrol atas pengetahuan, pengalaman yang bersifat empiris, teknik organisasi, hubungan dengan pelanggan dan keahlian profesional, hal tersebut akan memberikan keunggulan kompetitif bagi perusahaan". Bukh et al. (dalam Ulum 2008:4) mengemukakan pengertian intellectual capital sebagai berikut "sumber daya pengetahuan dalam bentuk karyawan, pelanggan, proses atau teknologi yang mana perusahaan dapat menggunakannya dalam proses penciptaan nilai bagi perusahaan. 
Peneliti terdahulu pada umumnya menyatakan bahwa intellectual capital terdiri dari tiga komponen utama (Sveiby, 1997; Brooking, 1997; Edvinsson dan Malone, 1997; Bontis, 1998; Sullivan, 2000), yaitu: 1) Human capital adalah inti dalam intellectual capital. Garcia-Meca (dalam Choong, 2008) menyatakan "human capital berhubungan dengan keahlian, bakat, dan sikap karyawan yang dilaporkan secara luas". Selanjutnya Bontis (2000:4) mengemukakan bahwa human capital adalah "kombinasi dari pengetahuan, keahlian, kemampuan melakukan inovasi, dan kemampuan menyelesaikan tugas, meliputi nilai perusahaan, kultur dan filsafatnya"; 2) Structural capital. Wang dan Chen (2008) mendeskripsikan bahwa "structural capital memiliki hubungan dengan sistem dan struktur perusahaan yang dapat membantu karyawan untuk mencapai kinerja intelektual maksimal mereka, sehingga kinerja perusahaan secara keseluruhan dapat meningkat". Selanjutnya Wang dan Chan (2008) mengklasifikasian structural capital menjadi budaya perusahaan, struktur organisasi, pembelajaran organisasi, proses operasional perusahaan dan sistem informasi. Lebih jauh Edvinsson dan Malone (dalam Lonnqvist, 2002: 285) memisahkan structural capital menjadi innovation capital dan process capital. 3) Relational capital. Belkaoui (dalam Ariawan, 2003:39) mendefinisikan relational capital sebagai "semua sumber daya yang berkaitan dengan hubungan pihak-pihak eksternal perusahaan, misalnya pelanggan, supplier atau partner dalam penelitian dan pengembangan". Lebih jauh Belkaoui (dalam Ariawan, 2003:39) menyatakan bahwa "relational capital terdiri dari bagian human dan structural capital yang terlibat dalam hubungan perusahaan dengan para stakeholder perusahaan, yaitu kreditor, supplier, konsumen, dan investor". Sedangkan Petrash (1996:365) mengemukakan relational capital "mencerminkan hubungan dengan pihak luar organisasi, seperti koneksi, loyalitas pelanggan, dan hubungan yang baik dengan supplier".

Metode VAICTM dikembangkan oleh Pulic (1998), di desain untuk menyajikan informasi mengenai value creation effciency dari aset berwujud (tangible asset) dan aset tidak berwujud (intangible asset) yang dimiliki perusahaan. Model ini dimulai dengan kemampuan perusahaan untuk menciptakan value added. Value added adalah indikator paling objektif untuk menilai keberhasilan bisnis dan menunjukan kemampuan perusahaan dalam penciptaan nilai (Pulic dalam Maheran, 2007: 5). Value added dihitung sebagai selisih antara output dan input (Pulic dalam Maheran, 2007: 5).

Komponen utama dari VAIC ${ }^{\mathrm{TM}}$ yang dikembangkan Pulic (1998) tersebut dapat dilihat dari sumber daya perusahaan, yaitu physical capital (VACA - Value Added Capital Employed), human capital (VAHU - Value Added Human Capital), dan structural capital (STVA - Structural Capital Value Added). VAIC $^{\text {TM }}$ juga dikenal sebagai Value Creation Efficiency Analysis, dimana merupakan sebuah indikator yang dapat digunakan dalam menghitung efisiensi nilai yang dihasilkan dari perusahaan yang didapat dengan menggabungkan CEE (Capital Employed Efficiency), HCE (Human Capital Efficiency), dan SCE (Structure Capital Efficiency) Pulic (dalam Ulum, 2008:28).

Sucipto (2003:2) mendefinisikan kinerja keuangan adalah "penentuan ukuran-ukuran tertentu yang dapat mengukur keberhasilan suatu perusahaan 
dalam menghasilkan laba". Lebih lanjut Elanvita (2008:36) menyatakan "tujuan perusahaan akan sulit tercapai bila perusahaan tersebut tidak bekerja secara efisien, sehingga perusahaan tidak mampu bersaing dengan perusahaan pesaing baik langsung maupun tidak langsung.

Chen et al. (2005:165) menyatakan Return On Asset (ROA) adalah "merefleksikan keuntungan bisnis dan efisiensi perusahaan dalam pemanfaatan total asset". Rasio ROA mewakili rasio profitabilitas, yang mengukur kemampuan perusahaan untuk menghasilkan laba dengan menggunakan total aset yang dimiliki perusahaan. Laba menjadi indikator kemampuan perusahaan dalam memenuhi kewajiban serta merupakan bagian dalam proses penciptaan nilai perusahaan (Suhendah, 2007:9).

Menurut Firrer dan William (2003:348) Asset Turn Over (ATO) merupakan "rasio dari total pendapatan terhadap total aset". Rasio ini mewakili produktivitas yang mengukur efektivitas perusahaan dalam menggunakan atau memanfaatkan sumber daya yang dimiliki perusahaan untuk menghasilkan pendapatan. Semakin besar pemanfaatan penggunaan total aset baik tangible asset maupun intangible asset seperti intellectual capital yang dimiliki maka akan meningkatkan pendapatan perusahaan (Firrer dan William, 2003:348). Produktivitas menggambarkan hubungan antara tingkat operasi perusahaan dengan aset yang dibutuhkan untuk menunjang kegiatan operasi perusahaan.

Rasio MB mewakili nilai pasar yang mengukur tingkat ketertarikan para investor terhadap harga saham tertentu. Rasio MB dihitung dengan membandingkan nilai pasar (market value) dengan nilai bukunya (book value). Nilai pasar biasanya memiliki nilai di atas nilai buku karena nilai pasar mencerminkan ekspektasi investor atas prospek ekonomi suatu perusahaan di masa akan datang. Oleh karena itu diperlukan metode untuk mengidentifikasi aset tersembunyi tersebut, yaitu intellectual capital (Firrer dan William, 2003:348).

Intellectual capital merupakan sumber daya penting yang dapat digunakan untuk menciptakan efisiensi organisasi, efektivitas, produktivitas, dan inovasi lebih baik dibandingkan dengan physical capital dan financial capital. Intellectual capital merupakan kunci penentu nilai dan kinerja perusahaan (Bontis, 2002). Pengaruh intellectual capital dengan kinerja keuangan perusahaan telah dibuktikan secara empiris oleh beberapa peneliti dalam berbagai pendekatan baik di Indonesia maupun luar Indonesia. Penelitian pertama di awali oleh Bontis pada tahun 1998 dengan melakukan eksplorasi hubungan antara komponen-komponen intellectual capital (human capital, customer capital, dan structural capital). Selanjutnya Bontis et al. melakukan penelitian kembali pada tahun 2000 dalam penelitiannya menemukan bahwa hubungan intellectual capital tergantung pada sektor industrinya.

Firer dan Williams (2003) melakukan penelitian dengan menggunakan objek 75 perusahaan yang go public di Afrika Selatan. Di dalam penelitiannya, intellectual capital diproksikan dengan VAIC ${ }^{\mathrm{TM}}$ dan diuji pengaruhnya terhadap kinerja perusahaan. Hasil dari penelitian tersebut menunjukkan bahwa intellectual capital hanya berpengaruh terhadap Asset Turn Over (ATO) dan Market to Book Value (MB), sedangkan Return On Asset (ROA) tidak. Sedangkan penelitian Chen et al. (2005) yang merupakan pengembangan dari penelitian Firer dan Williams 
(2003) menggunakan sampel 4.254 perusahaan go public di Taiwan Stock Exchange. Penelitian ini menggunakan variabel Market to Book Value (MB) dan kinerja keuangan yang diproksikan oleh Return On Equity (ROE), Return On Asset (ROA), Grownth Revenue (GR), Employee Performance (EP), serta menambahkan variabel R\&D (Research and Development) sebagai instrument penguat VAIC ${ }^{\mathrm{TM}}$. Pada penelitian ini Chen et al. (2005) menghubungkan intellectual capital dengan nilai pasar dan kinerja perusahaan. Hasilnya menunjukkan bahwa intellectual capital memiliki hubungan positif dengan nilai pasar, dan R\&D berpengaruh terhadap kinerja perusahaan. Selanjutnya, Ulum (2008) melakukan penelitian terhadap 130 bank go public dan bank yang belum go public di Indonesia tahun 2004 - 2006 yang secara rutin (tri wulan) melaporkan posisi keuangannya kepada Bank Indonesia (BI). Hasil dari penelitian ini menunjukkan adanya pengaruh intellectual capital yang diproksikan dengan $\mathrm{VAIC}^{\mathrm{TM}}$ signifikan terhadap kinerja perusahaan.

Berdasarkan pengembangan penelitian dapat diketahui bahwa terdapat pengaruh intellectual capital terhadap kinerja keuangan perusahaan, hipotesis yang dapat dirumuskan dalam penelitian ini adalah:

$\mathrm{H}_{1}$ : intellectual capital berpengaruh secara positif terhadap profitabilitas (ROA). $\mathrm{H}_{2}$ : intellectual capital berpengaruh secara positif terhadap produktivitas (ATO).

$\mathrm{H}_{3}$ : intellectual capital berpengaruh secara positif terhadap nilai pasar (MB).

\section{Metode Penelitian}

Populasi dalam penelitian ini adalah perusahaan retail yang terdaftar di Bursa Efek Indonesia (BEI) tahun 2009-2011. Sedangkan, sampel sengaja dipilih agar dapat mewakili populasi yang memenuhi kriteria tertentu sesuai dengan penelitian berjumlah 7 (tujuh) perusahaan retail. Ketujuh perusahaan tersebut memenuhi kriteria sampel berikut ini: 1) Perusahaan yang terdaftar di BEI selama tahun 2009-2011, 2) Perusahaan yang memiliki laba bersih positif, 3) Perusahaan tidak delisting dari BEI selama periode tahun 2009 - 2011. 4) Perusahaan yang mempublikasikan laporan keuangan yang telah di audit selama 3 tahun, yaitu tahun 2009-2011.

Berdasarkan pengertian di atas, maka sampel memenuhi kriteria dari 20 (dua puluh) perusahaan adalah 7 (tujuh) perusahaan retail yang ada di BEI sub sektor retail trade.

Pada penelitian ini analisis data yang dilakukan adalah analisis deskriptif dan analisis statistik. Analisis deskriptif untuk menganalisis tentang pengaruh intellectual capital terhadap kinerja keuangan. Sedangkan, analisis statistik untuk menganalisis data sampel yang digunakan untuk pengujian hipotesis. untuk menganalisis data-data yang telah diperoleh dan dianalisis lebih lanjut dan untuk pengujian hipotesis.

Sedangkan pengujian hipotesis yang digunakan dalam analisis ini adalah analisis korelasi person, analisis regresi linier sederhana, uji $t$, dan koofesien determinasi. Sebelum melakukan analisis regresi, data yang telah terkumpul terlebih dahulu dianalisis dengan uji asumsi klasi. Uji asumsi klasi yang digunakan pada penelitian ini adahal normalitas, autokorelasi, heteroskedastisitas, dan liniearitas 


\section{Hasil dan Pembahasan}

Jumlah pengamatan pada sampel $(\mathrm{N})$ berjumlah 21 , diperoleh nilai nilai rata-rata (mean) Intellectual capital yang diproksikan dengan VAIC ${ }^{\text {TM }}$ sebesar 2,97. Besarnya nilai terkecil untuk VAICTM adalah 1,26 sedangkan nilai terbesarnya adalah 11,89 dengan standar deviasi sebesar 2,24. Standar deviasi dan nilai mean memiliki perbedaan yang tidak terlalu mencolok yaitu sebesar 0,73 mengindikasikan bahwa kesenjangan antara VAIC ${ }^{\text {TM }}$ tertinggi dan terendah tidak terlalu besar.

Untuk Variabel dependen dalam penelitian ini, nilai rata-rata (mean) dari ROA, ATO, dan MB berturut-turut sebesar 0,$10 ; 1,49 ; 1,28$. Nilai terkecil dari ROA, ATO, dan MB adalah 0,$01 ; 0,75 ; 181,68$ sedangkan nilai terbesarnya adalah 0,$51 ; 2,45 ; 4842,63$ dengan standar deviasi sebesar 0,$11 ; 0,53 ; 1259,13$.

Alat analisis yang digunakan dalam penelitian ini adalah alat analisis regresi linier sederhana. Sebelum melakukan uji regresi, data yang terkumpul dianalisis terlebih dahulu dengan melakukan uji asumsi klasik. Uji asumsi klasik yang digunakan pada penelitian ini adalah normalitas, heteroskedastisitas, autokorelasi, dan liniearitas. Pada penelitian ini semua uji asumsi klasik telah dilakukan dan diperoleh hasil bahwa model penelitian telah terbebas dari autokorelasi, heteroskedastisitas, data normal, dan model liniear. Pengujian hipotesis dilakukan dengan menggunakan analisis korelasi person, analisis regresi linear sederhana, uji t, dan koefisien determinasi.

Hasil perhitungan korelasi pearson Tabel 2 menunjukkan arah korelasi positif antara VAIC ${ }^{\mathrm{TM}}$ dan ROA. Besar korelasi 0,867 yang diatas 0,5. Dengan menganggap angka korelasi diatas 0,5 adalah korelasi yang kuat, dapat diartikan ROA berkorelasi kuat dengan VAICTM .

Dari Tabel 3 diperoleh model regresi dengan persamaan $\mathrm{Y}=-0,28+$ $0,042 \mathrm{X}$. Dari persamaan regresi tersebut terlihat tanda (+) yang menggambarkan adanya pengaruh positif dari variabel VAICTM terhadap variabel ROA.

Berdasarkan Tabel 4 diketahui bahwa nilai t hitung sebesar 8,834. Nilai t hitung lebih besar dari t tabel $(8,834>2,093)$, maka Ho ditolak yang berarti Intellectual capital berpengaruh secara positif terhadap ROA. Nilai signifikansinya sebesar 0,000 . Karena nilai signifikannya lebih kecil dari 0,05 $(0,000<0,05)$ maka Intellectual capital berpengaruh signifikan terhadap ROA.

Berdasarkan Tabel 5 besarnya angka koefisien determinasi $R^{2}$ (R square) adalah 0,823 atau dalam bentuk presentasi sama dengan 82,3\%. Dari angka tersebut dapat disimpulkan bahwa Intellectual capital mempengaruhi ROA sebesar $82,3 \%$ sisanya sebesar 17,7\% dipengaruhi oleh variabel-variabel lain.

Hasil Perhitungan Tabel 2 menunjukkan arah korelasi negatif antara VAICTM dan ATO. Besar korelasi -0,472 yang dibawah 0,5. Dengan menggangap angka korelasi dibawah 0,5 adalah korelasi yang lemah, dapat diartikan ATO berkorelasi lemah dengan VAICTM.

Dari Tabel 6 diperoleh model regresi dengan persamaan $\mathrm{Y}=1,819$ $0,110 X$. Dari persamaan regresi tersebut terlihat tanda (-) yang menggambarkan adanya pengaruh negatif dari variabel VAIC ${ }^{\text {TM }}$ terhadap variabel ATO, sehingga ini berarti bahwa Intellectual capital berpengaruh negatif terhadap ATO. 
Berdasarkan Tabel 7 diketahui bahwa nilai t hitung sebesar -2,332. Nilai $\mathrm{t}$ hitung lebih kecil dari t tabel $(-2,332<2,093)$, maka Ho diterima yang berarti Intellectual capital tidak berpengaruh positif terhadap ATO. Nilai signifikansinya sebesar 0,031. Karena nilai signifikannya lebih kecil dari $0,05(0,031<0,05)$ maka Intellectual capital berpengaruh signifikan terhadap ATO.

Berdasarkan Tabel 8 besarnya angka koefisien determinasi $R^{2}$ (R square) adalah 0,224 atau dalam bentuk presentasi sama dengan 22,4 \%. Dari angka tersebut dapat disimpulkan bahwa Intellectual capital mempengaruhi ATO sebesar 22,4\% sisanya sebesar 77,6\% dipengaruhi oleh variabel-variabel lain.

Hasil perhitungan Tabel 2 terhadap MB menunjukkan arah korelasi positif antara VAICTM dan MB. Besar korelasi 0,012 yang dibawah 0,5. Dengan menggangap angka korelasi dibawah 0,5 adalah korelasi yang lemah, dapat diartikan bahwa MB berkorelasi lemah dengan VAICTM.

Dari Tabel 9 diperoleh model regresi dengan persamaan $\mathrm{Y}=1259,776+$ $6,612 \mathrm{X}$. Dari persamaan regresi tersebut terlihat tanda (+) yang menggambarkan adanya pengaruh positif dari variabel VAIC ${ }^{\mathrm{TM}}$ terhadap variabel MB.

Berdasarkan Tabel 10 diketahui bahwa nilai t hitung sebesar 0,051. Nilai t hitung lebih kecil dari t tabel $0,051<2,093$ ), maka Ho diterima yang berarti Intellectual capital tidak berpengaruh positif terhadap MB. Nilai signifikansinya sebesar 0,960. Karena nilai signifikannya lebih besar dari 0,05 $(0,960>0,05)$ maka Intellectual capital tidak berpengaruh signifikan terhadap MB.

Berdasarkan Tabel 11 besarnya angka koefisien determinasi $R^{2}$ (R square) adalah 0,000256 atau dalam bentuk presentasi sama dengan 0,0256\%. Dari angka tersebut dapat disimpulkan bahwa Intellectual capital mempengaruhi MB sebesar $0,0256 \%$ sisanya sebesar $99,9744 \%$ dipengaruhi oleh variabel-variabel lain.

\section{Simpulan}

Berdasarkan data yang diperoleh dan hasil analisis yang dilakukan pada penelitian ini, maka dapat disimpulkan hal-hal sebagai berikut :

a. Semakin tinggi intellectual capital, maka profitabilitas perusahaan akan semakin meningkat; berlaku sebaliknya jika intellectual capital rendah, maka profitabilitas perusahaan akan semakin menurun. Menurut pendekatan resource based theory, intellectual capital merupakan hal yang sangat penting agar memiliki keunggulan kompetitif dari perusahaan pesaing. Hasil temuan pada penelititian ini konsisten dengan Chen et al (2005), Tan et al (2007), dan Ting dan Lean (2009).

b. Penolakan terhadap Hipotesis ke-2 dapat disimpulkan bahwa intellectual capital berpengaruh secara negatif dan signifikan terhadap produktivitas (ATO). Hal ini sesuai dengan Nerdrum (2001) Pengaruh negatif terjadi karena perusahaan yang telah menggangarkan beban karyawan tinggi berharap akan mendapatkan value added yang tinggi dari karyawan, tetapi anggaran yang tinggi jika tidak diimbangi dengan pelatihan dan training justru akan menurunkan produktivitas perusahaan. Karyawan yang kurang efektif dan efisien dalam mengelola sumber daya yang dimiliki perusahaan akan menurunkan produktivitas. Hasil penelitian ini sejalan dengan penelitian Suhendah (2007) dan Tarigan (2011). 
c. Penolakan terhadap Hipotesis ke-3 dapat disimpulkan bahwa intellectual capital tidak berpengaruh dan signifikan terhadap nilai pasar (MB). Hal ini sesuai dengan Sunarsih dan Mendra (2010) yaitu penghargaan pasar pada suatu perusahaan lebih didasarkan pada sumber daya fisik yang dimiliki, investor cenderung tidak menitikberatkan pada sumber daya intelektual yang dimiliki perusahaan. Hasil ini konsisten dengan penelitian Najibulah (2005) yang menunjukkan bahwa para investor menilai perusahaan hanya mempertimbangkan aset fisik.

\section{Saran}

Berdasarkan simpulan yang telah penulis sampaikan diatas, terdapat saransaran untuk penelitian selanjutnya sebagai berikut:

a. Penelitian selanjutnya disarankan untuk memperluas sampel tidak hanya pada satu industri saja, melainkan seluruh perusahaan yang terdaftar di Bursa Efek Indonesia (BEI). Sehingga generalisasinya dan uji testnya lebih kuat, dan bisa menggambarkan intellectual capital pada seluruh perusahaan yang bergerak di bidang yang berbeda.

b. Penelitian selanjutnya disarankan untuk menguji hubungan antar indikator formatif intellectual capital yang diproksikan dengan VAIC ${ }^{\text {TM }}$, yang terdiri dari tiga indikator formatif VACA, VAHU, dan STVA. Sehingga dapat diketahui manakah diantara ketiga indikator formatif VAIC ${ }^{\text {TM }}$ yang paling berpengaruh terhadap kinerja keuangan perusahaan.

c. Penelitian selanjutnya disarankan untuk menambah periode waktu penelitian, karena periode waktu pada penelitian ini tergolong terlalu singkat sehingga sampel yang ada terlalu sedikit.

\section{Daftar Pustaka}

Abidin. (2000). "Upaya Mengembangkan Ukuran-ukuran Baru". Media Akuntansi. Edisi 7. Thn. VIII. pp. 46-47.

Accounting Principles Board. (1970). "Intangible Assets, APB Opinion 17". American Institute of Certified Public Accountants, New York, NY.

Accounting Standards Board. (1997). “Goodwill and Intangible Assets, FRS 10”. Accounting Standards Board, London.

Astuti, P.D. dan A. Sabeni. (2005). "Hubungan Intellectual Capital dan Business Performance". Proceeding SNA VII. Solo. pp. 694-707.

Ariawan. (2011). "Analisis Pengaruh Intellectual Capital Terhadap Kinerja Perusahaan; Suatu Analisis Dengan Pendekatan Partial Least Squares (Studi Pada Perusahaan yang Terdaftar di Bursa Efek Indonesia Tahun 2007-2010)". Juli. Semarang.

Ayu, Wahdikorin. (2010). "Pengaruh Modal Intelektual Terhadap Kinerja Keuangan Perusahaan Perbankan yang Terdaftar di Bursa Efek Indonesia (BEI) Tahun 2007-2009". Juli. Semarang.

Barney, J.B. (1991). "Firm resources and sustainable competitive advantage". Journal of Management. Vol. 17 No.1. pp. 99-120. 
Bontis, W.C.C. Keow, S. Richardson. (2000). "Intellectual capital and business performance in Malaysian industries". Journal of Intellectual Capital. Vol. 1 No. 1. pp. 85-100.

(2001). "Assessing knowledge assets: a review of the models used to measure intellectual capital". International Journal of Technology Management. Vol. 3 No. 1. pp. 41-60.

Bornemann, M, and K.H. Leitner. (2002). "Measuring and reporting intellectual capital: the case of a research technology organisation", Singapore Management Review. Vol. 24 No. 3. pp. 7-19.

Brennan, N, and B. Connell. (2000). "Intellectual capital: current issues and policy implications". Journal of Intellectual Capital Vol. 1 No. 3. pp. 206240.

Brooking, A. (1997). The Management Intellectual Capital. Long Range Planning, 30 (3), pp. 364-365

Bukh, C. Nielsen, P. Gormsen, and J. Mouritsen. (2005). "Disclosure of information on intellectual capital in Danish IPO prospectuses". Accounting, Auditing \& Accountability Journal. Vol. 18 No. 6. pp. 713732.

Caldeira M.M. and Ward J.M. (2003). "Using resource-based theory to interpret the successful adoption and use of information systems and technology in manufacturing small and medium-sized enterprises". European Journal of Information Systems. 12(2): 127-141.

Carlucci, D., Marr, B. \& Schiuma, G. (2004). "The knowledge-value chain: how intellectual capital impacts business performance".International Journal of Technology Management vol. 27. no. 6/7. pp. 575-590.

Chen, M.C., S.J. Cheng, Y. Hwang. (2005). "An empirical investigation of the relationship between intellectual capital and firms' market value and financial performance". Journal of Intellectual Capital. Vol. 6 N0. 2. pp. 159-176.

Choong, Kwee Keong. (2008) "Intellectual capital: definitions, categorization and reporting models".Journal of Intellectual Capital. Vol. 9 Issue: 4. pp. $609-638$.

Deegan, C. (2004). Financial Accounting Theory. Sydney:McGraw-Hill Book Company.

Edvinsson, L. and M. Malone. (1997). Intellectual Capital: Realizing Your Company's True Value by Finding Its Hidden Brainpower. New York: HarperCollins.

Friedlob, G. T., L. F. Schleifer and F. J. Jr Plewa (2002). Essentials of corporate performance measurement. New York: John Wiley and Sons.

Freeman, R.E., and Reed. (1983). "Stockholders and stakeholders: a new perspective on corporate governance". Californian Management Review. Vol 25. No. 2. pp. 88-106.

Firer, S., and S.M. Williams. (2003). "Intellectual capital and traditional measures of corporate performance". Journal of Intellectual Capital. Vol. 4 No. 3. pp. 348- 360. 
Gan K., Saleh Z.(2008). "Intellectual capital and corporate performance of technology- intensive companies: Malaysia evidence, Asian Journal of Business and Accounting", Vol. 1. Issue 1. pp. 113-130.

Grant, Robert. (2002). The Knowledge Based View of the Firm. Oxford: Oxford University Press.

Goh, P.C., and K.P. Lim. (2004). "Disclosing intellectual capital in company annual reports; Evidence from Malaysia". Journal of Intellectual Capital Vol. 5 No. 3. pp. 500-510.

Guthrie, J., and L.D. Parker. (1989). "Corporate social reporting: a rebuttal of legitimacy theory". Accounting and Business Research. Vol. 19 No. 76. pp. 343-52.

Garcia-Meca, E. (2005). "Bridging the gap between disclosure and use of Intellectual Capital information". Journal of Intellectual Capital. Vol. 6 No. 3.

Ghozali, Imam. (2006). Statistik Non-Parametrik; Teori \& Aplikasi dengan Program SPSS.Semarang: BP. Undip.

Ghosh, Santanu and Amitava Mondal. (2009). "Indian software and pharmaceutical sector IC and financial performance". Journal of Intellectual Capital. Vol.10 issue 3. pp. 369-388.

Hanafi. (2003). Analisis Laporan Keuangan. Yogyakarta: UPP AMP. YKPN

Hartono, Budi. (2001), "Intellectual Capital: Sebuah Tantangan Akuntansi Masa Depan", Media Akuntansi, Edisi 2, Thn VIII, hal 65-72.

Husnan, Suad \& Enny Pudjiastuti. 1993. Dasar Dasar Manajemen Keuangan.Yogyakarta: Amp YKPN.

Ikatan Akuntan Indonesia. (2002). Pernyataan Standar Akuntansi Keuangan No. 19. Jakarta: Salemba Empat.

International Accounting Standards Board. (2004). "Summary of IAS 38". available online at: www.iasplus.com. (14 Februari 2012).

International Federation of Accountants. (1998). "The Measurement and Management of Intellectual Capital". available online at: www.ifac.org. (14 Februari 2012).

Iswati, Sri dan M. Anshori. (2006). The Influence of Intellectual Capital to Financial Performance at Insurance Companies in Jakarta Stock Exchange (JSE). 13th Asia Pacific Management Conference. Melbourne, Australia.

Jogiyanto, HM. (2007). Metodologi Penelitian Bisnis. Yogyakarta: BPFE.

Kamath, G.B. (2007). "The intellectual capital performance of Indian banking sector". Journal of Intellectual Capital. Vol. 8 No. 1. pp. 96-123.

Kaplan, R.S. and D.P. Norton. (1992). "The balanced scorecard-measures that drive performance". Harvard Business Review. Vol. 70 No. 1. pp. 71-9.

Kotter, J.P., and Heskett, J.L.(1992). Corporate Culture and Performance. New York:Free Press.

Kuryanto, Benny dan Muchamad Syafruddin. (2008). "Pengaruh Modal Intelektual Terhadap Kinerja Perusahaan". Semarang.

Lev, B. (2001).“Intangibles: management, measurement and reporting Brooking”. Washington, D.C:Institution Press. 
Maheran. (2007). Intellectual Capital Efficiency And Firm's Performance: Study On Malaysian Financial Sectors. Kelantan: Faculty of Business Management.

Martin, JD and Akin Sayrak. (2001). "Corporate diversification and shareholder value: a survey of recent literature". Journal of Corporate Finance. Vol 9. Issue 1. Januari 2003. pp. 37-57.

Marr, Bernard, Dina Gray and Andy Neely. (2003). "Why do firms measure their intellectual capital ?". Journal of Intellectual Capital. Vol. 4 Issue 4. pp. $441-464$.

Mavridis, D.G. (2004). "The intellectual capital performance of the Japanese bankingsector". Journal of Intellectual Capital. Vol. 5 No. 3. pp. 92-115.

Mualim, Nurcholis. (2009). "Pengaruh Intellectual Capital Terhadap Kinerja Keuangan Pada Perusahaan yang Terdaftar di Bursa Efek Indonesia”. Desember. Bandung.

Kuncoro, Mudrajat. (2003). Manajemen keuangan Internasional. Yogyakarta: BPFE.

Lonnqvist, A and Mettanen, P. (2002). "Criteria of sound intellectual capital measures". www.tut.fi/units/tuta/teta/mittaritiimi/julkaisut/Icmeasures.pdf

Najibullah S., (2005). "An empirical investigation of the relationship between intellectual capital and firm's market value and financial performance in the context of commercial banks of Bangladesh, Working Paper, Independent University of Bangladesh", available at http://sb.iub.edu.bd/internship/autumn2005/0220175.pdf (28 September 2012).

Nazir, Muhammad. (2003). Metode Penelitian. Jakarta:Ghalia Indonesia.

Nerdrum, L. (1999).The Economics of Human Capital: A Theoretical Analysis Illustrated Empirically by Norwegian Data. Oslo:Scandinavian University Press.

Oliveras, Ester and Yulia Kasperskaya. (2002). "Reporting intellectual capital in Spain". Economics Working Papers 781, Department of Economics and Business, Universitat Pompeu Fabra.

Petty, P. and J. Guthrie. (2000). "Intellectual capital literature review: measurement, reporting and management". Journal of Intellectual Capital. Vol. 1 No. 2. pp. 155-75.

Petrash, G. (1996). "Dow's journey to a knowledge value management culture", European Management Journal. Vol. 14 No. 4. pp. 365-73.

Pitts R., and Lei, D. (2003). Strategic management: Building and sustaining competitive advantage. South-Western: Thompson.

Pulic, A. (1998). "Measuring the performance of intellectual potential in knowledge economy". Paper presented at the 2nd McMaster Word Congress on Measuring and Managing Intellectual Capital by the Austrian Team for Intellectual Potential. (1999). "Basic information on VAIC TM", available online at: www.vaicon.net. (14 Februari 2012).

(2000). "VAIC $\mathrm{TM}$ - an accounting tool for IC management". available online at: www.measuring-ip.at/Papers/ham99txt.htm (14 Februari 2012). 
Riahi-Belkaoiu, A. (2003). "Intellectual capital and firm performance of US multinational firms: a study of the resource-based and stakeholder views". Journal of Intellectual Capital. Vol. 4 No. 2. pp. 215-226.

Russel, J., Terborg, J. \& Powers M. (1985). "Organizational Performance and Organization Level Training and Support”. Personel Psychology, V.38, No:25, 41-63.

Santosa, Purbayu Budi dan Ashari. (2005). Analisa Statistik Dengan Microsoft Excell dan SPSS. Yogyakarta:Andi.

Santoso, Singgih. (2012). Aplikasi SPSS pada Statistik Parametrik. Jakarta: Elexmedia Komputindo.

Sawarjuwono, Tjiptohadi dan Agustine Prihatin Kadir. (2003). "Intellectual Capital: Perlakuan, Pengukuran dan Pelaporan (Sebuah Library Research)."JurnalAkuntansi dan Keuangan. Vol 5, No. 1, 31-51.

Sunarsih, Ni made dan Ni Putu Yuria Mendra (2010). "Pengaruh Modal Intelektual Terhadap Nilai Perusahaan Dengan Kinerja Keuangan Sebagai Variabel Interverning Pada Perusahaan yang Terdaftar di Bursa Efek Indonesia". Denpasar.

Sucipto. (2003). Penilaian Kinerja Keuangan. (online). available http://digilib.usu.ac.id (28 Agustus 2012).

Sugiyono.(2009). Statistika Untuk Penelitian.Bandung: Alfabeta. (2010). Metode Penelitian Bisniscetakan ke-15. Bandung: Alfabeta.

Suharsimi, Arikunto. (2006). Prosedur Penelitian Suatu Pendekatan Praktik. Jakarta: PT Ahdi Mahsatya.

Sullivan Jr., P.H. and P.H. Sullivan Sr. (2000). "Valuing intangible companies, an intellectual capital approach". Journal of Intellectual Capital. Vol. 1 No. 4. pp. 328-340.

Stewart, Thomas A. (1991), "Brainpower", Fortune June, page 53-55. (1997). "Intellectual Capital: The New Wealth of Organizations." New York: Doubleday.

Sveiby, K.E. (1997), The New Organizational Wealth: Managing and Measuring Knowledge-Based Assets, Berrett-Koehler, New York, NY. (2001). "Method for measuring intangible assets". available online at: www.sveiby.com/articles (14 Februari 2012).

Solikhah, B. (2010). "Pengaruh Intellectual Capital Terhadap Kinerja Keuangan, Pertumbuhan dan Nilai Pasar Pada Perusahaan Yang Tercatat di Bursa Efek Indonesia". Master Thesis. University of Diponegoro.

Sopiah, dan Syihabudhin. (2008). Manajemen Bisnis Ritel. Yogyakarta:Andi Offset.

Suhendah, Rousilita. (2007). "Pengaruh Intellectual Capital Terhadap Profitabilitas, Produktivitas, dan Penilaian Pasar Pada Perusahaan yang Go Public di Indonesia pada Tahun 2005-2007’. Juni. Jakarta.

Tan, H.P., D. Plowman, P. Hancock. (2007). "Intellectual capital and financial returns of companies. Journal of Intellectual Capital. Vol. 8 No. 1. pp. 7695. 
Tarigan, T. (2011). “Analisis Pengaruh Intellectual Capital Terhadap Kinerja Perusahaan Sektor Farmasi Yang Terdaftar di Bursa Efek Indonesia Tahun 2006-2010". Juli 2011. Semarang.

Teece, D.J. (2003). Essays in Technology Management and Policy. Singapore: World Scientific Publishing.

Ting, Irene Wei Kiong and Hooi Hooi Lean. (2009) "Intellectual capital performance of financial institutions in Malaysia".Journal of Intellectual Capital. Vol. 10 Issue 4. pp.588 - 599.

Ulum, I. (2007), "Pengaruh Intellectual Capital Terhadap Kinerja Keuangan Perusahaan Perbankan di Indonesia" Master Thesis, University of Diponegoro.

(2008). "Analisis Pengaruh Intellectual Capital Terhadap Kinerja Perusahaan; Suatu Analisis Dengan Pendekatan Partial Least Squares (Studi Pada Perusahaan yang Terdaftar di Bursa Efek Indonesia Tahun 2007-2010)". Juni. Semarang. (2009). "Intellectual Capital : Konsep dan Kajian Empiris".Yogyakarta:Graha Ilmu.

Wu, W.Y., Chang, M. L., \& Chen, C. W. (2008). "Promoting innovation through the accumulation of intellectual capital, social capital, and entrepreneurial orientation. $R \& D$ Management". 38(30). pp. 265-277.

Wang, W.Y. and Chang, C. (2005), "Intellectual capital and performance in causal models: evidence from the information technology industry in Taiwan", Journal of Intellectual Capital, Vol. 6 No. 2, pp. 222-36.

Yudianti, Ninik. (2000). "Pengaruh Kinerja Keuangan Terhadap Harga Saham Perusahaan Perbankan yang Tercatat di Bursa Efek Jakarta”. Juni. Malang.

Zeghal, D. and Maaloul, A. (2010) "Analyzing value added as an indicator of intellectual capital and its consequences on company performance", www.idx.com Journal of Intellectual Capital, 11 (1), 39-60. 